\title{
VALLE-INCLÁN Y EL TEATRO GALLEGO
}

\author{
Jose María Paz Gago
}

Universidad de La Coruña

En un excelente y ya viejo trabajo, muestra de lo que deben ser los estudios sobre teatro y los planteamientos comparatistas rigurosos, hacía Felicia Hardison una decepcionada afirmación: Teóricamenmte Valle-Inclán debería haber sido para la escena española lo que el Ubu Roi de Alfred Jarry fue para el teatro francés en 1896; sin embargo, Jarry con el tiempo tuvo seguidores, Valle-Inclán permanece solo (1967 en 1992: 181).

Esta triste conclusión quizás sea cierta para el caso de la historia del teatro español en la que, efectivamente, pocos dramaturgos fueron capaces de dar continuidad a la revolución teatral llevada a cabo por el arosano, quien se adelantó en un siglo a la evolución estética del teatro, al menos en España ${ }^{1}$. Desde la nueva perspectiva que nos da este movido final de centuria, momento en el que se ha empezado a representar el

${ }^{1}$ Idea expuesta por el dramaturgo Euloxio R. Ruibal en su texto inédito, «ValleInclán e o Teatro Galego». 
teatro de Valle con los medios y los planteamientos adecuados (Paz Gago, 1998: 51-53), podemos darnos cuenta de la trascendencia de una estética teatral que avanzó las experiencias vanguardistas, inventó el expresionismo e inspiró decisivamente la dramaturgia del absurdo, el movimiento teatral más importante de las décadas centrales del siglo, para aportar su propio sistema dramático, el esperpento.

Junto a este impacto intertextual de gran alcance, Valle creó escuela, y una escuela de enorme trascendencia, entre los dramaturgos de su tierra, en Galicia. Ya los fundadores del teatro gallego contemporáneo, Antón Vilar Ponte o Ramón Cabanillas, Castelao y Otero Pedrayo, tuvieron contacto directo con él, lo trataron con asiduidad en tertulias y conversaciones amistosas e incluso colaboraron con Don Ramón María en proyectos teatrales, recibiendo su influencia y magisterio de forma directísima. Ello hizo posible que la generación siguiente, la de la postguerra, siguiese el camino del esperpento, estética tan ligada a las peculiaridades socioculturales de Galicia y al complejo sistema de creencias y tradiciones de los gallegos. Figuras tan importantes como Álvaro Cunqueiro, Rafael Dieste o Eduardo Blanco Amor sostienen en sus respectivas obras dramáticas un vivo diálogo intertextual con el autor de Las Comedias Bárbaras.

Son dos esencialmente las isotopías temático-estilísticas que atraviesan radicalmente los esperpentos valleinclanianos, entrelazándose sorprendente y originalmente: lo cómico y lo macabro. El humor negro de Valle procede en línea directa del perfil sicológico y sociológico del hombre gallego, su peculiar retranca, la ambiguiedad de su proceder y su pensamiento, que produce irremisiblemente la situación cómica. Al mismo tiempo, la idiosincrasia del noroeste español, íntimamente ligada a la civilización celta anterior a la romanización, tiene como nota característica la familiaridad con el mundo del más allá, el trato cotidiano con las almas de los muertos, tema que se trata con una naturalidad y un sentido del humor poco corrientes en otros contextos culturales.

Quizás entre las mejores definiciones que se han dado del esperpento esté aquella que daba hace más de tres décadas Jean-Paul Borel (1966: 213): una hipertrofia de determinados aspectos de la sociedad que tiene como resultado una visión caricaturizada de cosas alternativamente cómicas y macabras, una combinación inseparable de lo sombrío, lo sangriento y la parodia. Esa fusión de lo cómico y lo macabro que fundamenta la estética del esperpento valleinclaniano es común a los dramaturgos gallegos que convivieron con su inventor o que, en todo caso, se convirtieron en sus verdaderos e inmejorables herederos literarios. 
Ya en el primer cuarto de siglo, los intelectuales y escritores que comienzan a forjar la cultura y la literatura del galleguismo, reivindican la figura de Valle-Inclán, a pesar de que éste había optado por escribir en español, abandonando definitivamente la lengua gallega.

Al criticar con dureza a los que montaban obras de dramaturgos españoles, Antón Vilar Ponte los incitará a representar obras gallegas de Valle-Inclán, repudiadas por empresarios y actores de Madrid, en castellano o vertidas al gallego. Tanto el regionalismo decimonónico como el galleguismo, desde Murguía hasta muy especialmente Castelao, defendieron y reivindicaron la obra de Valle, que este último con los ojos del alma veía escritas en gallego (cf. Cortezón, 1991: 331). Valle llamará a Castelao para hacer los figurines y la escenografía del montaje que Rivas Cherif pretendía realizar con Divinas Palabras, y el artista de Rianxo estará presente en 1933, junto a Margarita Xirgú, Enrique Borrás, el propio Rivas Cherif y el dramaturgo, en el Teatro Español de Madrid durante la lectura de la pieza. El propio Castelao pronunciará el histórico discurso Galicia y Valle-Inclán, publicado por el profesor Alonso Montero en 1971, reivindicando desde su exilio americano la figura y la obra de un autor gallego genial y universal, en cuyo lecho de muerte lo acompañaría el 6 de febrero de 1936.

No se limitó a la amistad y a las declaraciones la vinculación de las figuras del galleguismo histórico con Valle. Así, alguna de las piezas dramáticas del principal impulsor de las Irmandades da Fala, Antonio Villar Ponte, recogen la huella intertextual del teatro esperpéntico. Tanto Entre dous abismos (1920) como Nouturnio de medo e morte (1935) responden a esa línea estilística y temática. Mientras que la primera lleva el subtítulo genérico de farsada granguiñolesca y aborda humorísticamente un velatorio en el que resucita el muerto, la segunda contiene una breve y bien sintetizada intriga que evoca el cruento suceso de un triple asesinato expuesto a la manera del esperpentismo tremendista. Definida paratextualmente como bárbara anécdota por el propio autor, calificada también de granguiñolesca por el profesor Carballo Calero, Pillado y Lourenzo hablan de ensaio de peza tremebunda, quedando así confirmada su filiación esperpéntica y el realismo macabro de estirpe valleinclanesca que inspiró la redacción de ambas piezas ${ }^{2}$.

2 Recientemente ha aparecido una cuidada edición de ambas obras: Entre dous abismos y Nouturnio de medo e morte. Antón Villar Ponte, Ínsua López, E. X. (ed.), A Coruña: Universidade da Coruña, 1998. 
La puesta en escena por el Centro Dramático Galego en 1997, con dirección de Quico Cadaval, venía a confirmar esta caracterización. El montaje exhibía un cuidado trabajo actorial mediante movimientos estilizados y contundentes, especialmente adecuados a la violencia de la acción y a la nueva tradición esperpéntico-guiñolesca en la que el dramaturgo se inscribe.

\section{VALLE-INCLÁN Y EL TEATRO NóS: CASTELAO Y OTERO PEDRAYO}

En los presupuestos de la farsa esperpéntica se inserta también lo mejor de la producción del llamado Teatro Nós, en la terminología de Carballo Calero (1979) que denominaba así a la obra dramática de los componentes de esa importante generación: Alfonso Rodríguez Castelao y Ramón Otero Pedrayo, esencialmente.

En su estancia en París a comienzos de los años veinte, idea Castelao un Teatro de Arte para Galicia, fundamentado en los complejos elementos parateatrales que encierra la tradición folclórica gallega: el carnaval o Antroido, las leyendas sobre el mundo del más allá y los complejos ritos y creencias con él relacionados, los plantos y velatorios, la brujería...

De acuerdo con estés parámetros redacta Castelao su única obra dramática, Os vellos non deben de namorarse, editada por primera vez en el año $1953^{3}$, y a partir de sus sugerencias esboza Otero Pedrayo dieciséis esquemas de otras tantas farsas, más algunas otras posteriores. Como afirma en el Prólogo, Castelao recoge en Os vellos un argumento tradicional, el enamoramiento tardío de un viejo, dándole la forma de una farsa nueva, de una farsa contada á maneira galega, es decir, con el estilo popular del folclore de la Tierra. Otero Pedrayo conecta inmediatamente con las inquietudes de su compañero de tareas políticas y parlamentarias, con el proyecto de su colega de armas literarias en el impulso decidido a las letras nacionales iniciando su propia obra dramática. Bajo el título de Teatro de Máscaras, redacta un conjunto de esbozos de piezas dramáticas, publicadas a partir de

${ }^{3}$ Utilizamos la $8 .^{2}$ edición, Vigo: Galaxia, 1988. Para Teatro de Máscaras de Otero Pedrayo, A.I. Boullón y F.R. Tato (eds.), Vigo: Galaxia, 1989. 
1934, escribiendo posteriormente algunos diálogos bastante semejantes en concepción a aquéllas.

Tardíamente publicada, los tres Lances en que se divide $O s$ vellos constituyen una triple farsa de clara estirpe esperpéntica cuya estructura temática y formal no podía proceder exclusivamente del Teatro de Arte ruso, que Castelao conocerá directamente en la Unión Soviética en 1938, cuando acude al teatro oficial de Baku. Como reconoce uno de los mejores conocedores de la obra de Castelao, Valentín PazAndrade, estas experiencias «non explican sen mais a concepción trifocal da peza, nin as calidades formales que atesoura». Paz Andrade señala explícitamente la configuración dramatúrgica que exhibe una de las obras más importantes del teatro gallego contemporáneo: $o$ modelo de farsa esperpéntica a que se axusta, en curiosa sincronía con a macro-aportación de Valle-Inclán ao xénero (1982: 459).

Tal como declara su autor en el paratexto del prólogo, el tema central de la pieza es doble, el amor y la muerte, eros y tánatos: artimaña escenográfica onde xogan o amor e a morte de tres vellos imprudentes (1988: 7). En relación con los temas y motivos del nuevo teatro gallego que quiere iniciar, confiesa en su Correspondencia Castelao que ha tenido varias ideas, pero que todas son macabras (Grial, 52, 1976: 276). De hecho, Os vellos non deben de namorarse constituye una visión cómica de la consecuencia irreparable que conlleva la insensata aventura amorosa de tres viejos encaprichados con otras tantas jóvenes, una muerte augurada y obsesionante.

En el Lance Primero, una muerte humanizada advierte a Don Saturio sobre el funesto error de enamorarse a destiempo: non se esquenza de que os vellos que se namoran das mozas novas buscan a morte (p. 26). En el Tercero, el señor Fuco recibe diversos avisos y augurios de su propia muerte que llega a obsesionarle: Non tardaredes en ir detrás da miña caixa (p. 96), A morte anda conmigo dende fai algúns días (p. 97)... a miña vida cóntase por días ou cicáis por horas... non tardarei en comer terra (p. 98). La escena epilogal de la pieza es un cuadro inigualable del sarcasmo esperpéntico y el humor macabro con los tres viejos enamoradizos contándose sus cuitas en el cementerio. Parece indudable la funcionalidad de la particular estilística dramática de quien había sido su contertulio en el pontevedrés Café Moderno, el creador del esperpento.

Cada uno de los esbozos que conforman el Teatro de Máscaras, redactados por Ramón Otero Pedrayo en 1934, siguiendo las consig- 
nas estéticas de Castelao, constituyen verdaderos apuntes esperpénticos, al igual que otros textos posteriores, redactados a lo largo de su vida ${ }^{4}$. Personajes, núcleos temáticos, aspectos genéricos y estilísticos de las didascalias, atmósfera o espacios escénicos son literalmente valleinclanianos. La decadente hidalguía gallega, mendigos y truanes, clérigos mundanos y borrachos impenitentes, fantasmas y espectros, transitan por pazos y cementerios, lúgubres capillas o animadas plazas del mercado configurando un bien reconocible mundo escénico en el que se mezclan, en palabras de Manuel Lourenzo y Laura Tato (1997: 778), mitoloxía, superstición, maxia e relixión; a carlistada e o liberalismo; o realismo máis cru e o lirismo máis sentido; todo isto combinado co humor para crear as farsas máis orixinais do teatro galego.

El esbozo titulado A Estadea (la Santa Compaña), por ejemplo, entabla una íntima relación intertextual con el mundo y los personajes de las Comedias Bárbaras: un grupo de clérigos sacrílegos, tras una comilona pantagruélica, intenta profanar la tumba de una hidalga para robar sus joyas, acción que es impedida por la procesión de muertos de la capilla. Para Lourenzo y Tato (1997: 778), la pieza recrea de forma casi esperpéntica la brutalidad de la carlistada cuyo expolio es evitado por la Estadea que arrastrará consigo a los sacrílegos clérigos.

Como en ningún otro lugar, en $O$ fidalgo e a noite sobresale el humor macabro: cuando el hidalgo deja su casa y se adentra en la noche tenebrosa, recibe negros presagios: Vaino apañar a tristeira Compaña (p. 4), hasta que aparece una Santa Compaña simpática y habladora que se queja de su obligada inactividad y reclama su derecho a ser de nuevo la reina escalofriante de la noche gallega (p. 7). Situación grotesca es también la que presenta $O$ desengano do Prioiro ou $O$ pasamento da alegría, co grande auto epilogal e xusticieiro dos féretros de Floravia, cuyo contenido consiste en la sorpresa del Prior y su mayordomo cuando realizan una visita a Floravia, capital del Ribeiro: la gozosa y floreciente industria del vino ha sido sustituida por una nueva actividad industrial, la fabricación de féretros. En clave satírica y de humor negro, la pieza termina con la destrucción de tan mortífera industria.

4 O desengano do prioiro (1952), Traxicomedia da Noite dos Santos (1960), O fidalgo e a noite (1970), Noite compostelá (1973). También se incluyen otras piezas en el volumen Teatro ignorado, editado por Aurora Marco (1991). 


\section{EL TEATRO GALLEGO DE LA POSTGUERRA: ÁLVARO CUNQUEIRO}

El dramaturgo más importante del teatro gallego contemporáneo, Álvaro Cunqueiro, recibe de forma directísima la brillante lección dramatúrgica de Valle-Inclán, con quien incluso estaba emparentado. Ufanándose de esa familiaridad reconocía y reivindicaba la estrecha relación que en lo literario y en lo teatral sostuvo con su ilustre primo: En primeiro lugar, teño que manifestar que me satisface ser parente de Valle-Inclán, pero non remoto, senón bastante próximo, pois coñecino e tratámonos familiarmente como curmáns. Por outra parte, e súa obra influíu moito en min, especialmente o Valle do teatro das súas Comedias Bárbaras ${ }^{5}$.

Sus primeras experiencias surrealistas y el conocimiento profundo de la estética deformante del esperpento van a permitir que, en los años cincuenta, Cunqueiro participe en la fundación del gran movimiento teatral de la segunda mitad del siglo, el Teatro del Absurdo (Paz Gago, 1999: 70 y ss.). El escritor gallego, a quien también se debe en narrativa la invención del realismo maravilloso de estirpe genuinamente gallega, tiene el mérito de iniciar una de las líneas más profundas y fecundas de este movimiento, la que recoge el lejano precedente shakesperiano parodiándolo genialmente. En efecto, las dos geniales parodias cunqueirianas del dramaturgo de Avon, Romeo e Xulieta, famosos namorados de 1956, y $O$ incerto señor don Hamlet de 1959 inician una fecunda serie de versiones paródicas que van desde el Rosencrantz and Guildenstern are Dead, de 1965 o Hamlet's Dogg, Macbeth's Cahoot finalizada en 1979, ambas de Tom Stoppard, hasta el Macbett de Ionesco, de 1972.

La generación de dramaturgos que agrupa a Ionesco, Adamov, Tardieu, Boris Vian o Samuel Beckett surge en los años de la Postguerra Mundial con el empeño de violar las normas convencionales del teatro y en inventar un lenguaje nuevo, que quiebra las reglas de la sintaxis y de la semántica, de la razón y de la convención. Se trata

5 En Sahara Semanario, 29.9.1969. Según testimonio de Dionisio Gamallo Fierros, Valle habló en varias ocasiones de Cunqueiro como firme promesa de las Letras, negando el pretendido parentesco. De todos modos, buena parte de las familias gallegas de alcurnia proceden del tronco de los Montenegro, apellido perteneciente a la madre de Álvaro Cunqueiro. 
de un discurso teatral imsólito, desposeído de su función comunicativa, de forma que produce en el espectador un efecto de irrisión y de extrañeza, de comicidad y de absurdez. En 1956 ensaya Ionesco su primera definición de lo que llama un théâtre de la dérision; enunciando en respuesta a las críticas brechtianas de Roland Barthes y de Bernard Dort sus principios fundamentales: la parodia, lo grotesco y lo ridículo (cf. Jacquart, 1991: 82), principios idénticos a aquéllos que fundamentan la estética valleinclaniana.

Paul-Louis Mignon describe la nueva dramaturgia del Absurdo como el espectáculo de situaciones, momentos o episodios esenciales de la existencia, representados con un estilo que él define como naturalismo fantástico o simbólico (1986: 187). Ninguna fórmula más adecuada para referirse a la obra literaria tanto de Valle como de Cunqueiro que ésta en la que Mignon sintetiza un teatro poético y simbólico, transformado insólitamente por la comicidad, lo grotesco y la parodia, como consecuencia de la introducción de lo fantástico, lo sobrenatural y lo macabro en la vida cotidiana.

Sin duda, la pieza más esperpéntica de Cunqueiro es $A$ noite vai coma un rio, redactada en una primeira versión en 1960 y publicada más tarde en la revista Grial. Esta pieza editada en 1965 será integrada en castellano en la novela Un hombre que se parecía a Orestes (1969), como texto de la autoría del dramaturgo Filón o Mozo, transgresión de las fronteras entre los géneros canónicos, habitual en el escritor gallego.

Versión convexa del mito literario de Don Juan, es su antagonista femenina, Doña Inés, la que busca desesperadamente el amor verdadero, entregándose con indisimulada facilidad a diferentes hombres: un músico, un capitán y un mendigo, que la rechazan irremediablemente. Su actitud exhibe, con humor patético y macabro, la desconfiguración tanto del amor platónico femenino como de los amoríos machistas que representa el donjuanismo romántico. Parodia de la parodia, ironía de la ironía, Doña Inés acaba encontrando el objeto de su pasión insatisfecha en un muerto, el cadáver de un hombre irremisiblemente mujeriego.

El humor absurdo y grotesco constituye la clave de esta pieza interpretada como simbolista por Carballo Calero, comedia poética para Manuel Lourenzo (1991: 37), como síntesis de lirismo y humor, sueño y realidad, decadentismo amable y esperpentismo por Vilavedra (1991: 132). Como siempre en Cunqueiro, el contraste entre idealismo 
platónico y sensualidad carnal, atmósfera onírica y realismo descarnado, produce los efectos de extraña y grotesca comicidad que debe percibir tanto el lector como el espectador competentes.

El colmo de lo equívoco y lo paródico se produce en la Segunda Jornada, en la que se dan cita los rasgos absurdos y grotescos más literalmente valleinclanianos: tras un planto tradicional lleno de comicidad hilarante, una Doña Inés inflamada por la pasión se declara, ante la viuda legal y la ilegal, a este muerto demasiado aficionado a las mujeres, sugiriendo un acto de necrofilia.

El estreno en Lugo de la ambiciosa puesta en escena por la Compañía del Centro Dramático Galego, en 1986, suscitó una polémica sobre las claves interpretativas de la pieza. Si el director Xulio Lago ofrecía una lectura escénica del texto en clave de tragicomedia romántica decadentista, incidiendo en los elementos mágicos e idealistas, el crítico y dramaturgo Miguel Anxo Murado echaba de menos los aspectos cómicos, lúdicos y farsescos de la obra ${ }^{6}$, esenciales y fundamentales.

También A. Prieto, más incisivo, criticaba la concepción del espectáculo como una tragedia, interpretación que impediría ver la majestuosidad irónica y esperpéntica de la creación cunqueiriana (El Ideal Gallego, 19.9.86). El crítico Damián Villalaín (1993: 489) incidía en ese punto de vista al mostrar su desacuerdo con una opción unilateral por la tragedia romántica que descuidaría otros registros menos evidentes. En A noite vai coma un río, Álvaro Cunqueiro sigue la lección de su admirado Valle, reinterpretando en clave paródica los mecanismos catárticos de la tragedia para ofrecernos una tragicomedia hilarante, en la que se entrelazan sin solución de continuidad lo cómico y lo macabro, el amor y el engaño, el llanto y la risa.

En la senda de los grandes renovadores de la escena española del XX, Lorca y Valle, también Eduardo Blanco Amor escribe, en las décadas de los treinta y los cuarenta, sus farsas americanas, que él mismo denominará simples divertimentos escénicos. Dramaturgo circunstancial, esta colección de Autos y Farsas para títeres, escrita originalmente en castellano, constituye una aportación teatral de interés desigual, aunque para Laura Tato su labor es una aportación fundamental a nuestra dramaturgia, en la línea de los valores plásticos y estéticos.

6 M.A. Murado, «Na estreia de A noite vai coma un río», A Nosa Terra, 299, 1986. «O Teatro poético de Cunqueiro», La Voz de Galicia, 14.9.86. «O estreo de A noite vai coma un río», Cuaderno de Cultura. La Voz de Galicia, 18.9.86. 
Una de las piezas más importantes del conjunto es sin duda Un refaixo para Celestina, inteligente parodia de ese texto genéricamente híbrido que constituye, a su vez, una parodia de la novela sentimental española del XV. En ella nos ofrece Eduardo Blanco Amor, definiéndola como fantasmagoría de espectros, una esperpéntica y divertida versión de la Celestina en la que Melibea es todavía mucho menos recatada y Calisto todavía mucho más interesado de lo que lo son en la (supuesta) obra de Rojas.

\section{VALLE-INCLÁN Y EL TEATRO GALLEGO ACTUAL}

En los años setenta, coincidiendo con la agonía del franquismo y con la reinstauración de la democracia en España, se produce en Galicia un resurgimiento de la actividad dramática, con un primer intento de darle cierta estabilidad y profesionalidad. Este fenómeno teatral está estrechamente vinculado a la Mostra de Teatro de Ribadavia, organizada por la Agrupación Cultural Abrente de Ribadavia. Se forman Compañías profesionales, se redactan y se ponen en escena textos de autores gallegos, a la mayoría de los cuales se ha otorgado el Premio Abrente convocado dicha Agrupación, de forma que empiezan a sentarse las bases de una estructura teatral, literaria y editorial, cada vez más acorde con la realidad sociocultural gallega. Dramaturgos como Euloxio R. Ruibal, Manuel Lourenzo, Roberto Vidal Bolaño, Francisco Taxes o Camilo Valdeorras configuran un espontáneo y valioso movimiento teatral que hoy se conoce como Xeración Abrente.

Es en este contexto donde trata de configurarse una Poética teatral acorde con la peculiaridad socio-cultural gallega, recurriendo, como lo había hecho la Generación Nós pero con mayor radicalidad, a las formas parateatrales de los ritos cristianos y precristianos, la ritualidad de la muerte, las prácticas de la magia y el ocultismo, las farsas y combates del Antroido, las mascaradas ancestrales y otros ritos festivos o funerarios como letanías, entierros, Compañas, quemas, sermones, testamentos de Carnaval, hechizos y conjuros. Todos estos materiales reciben un tratamiento no parateatral sino teatral, son recuperados no con un interés etnológico o antropológico sino como elementos escénicos en sí, como ingredientes esenciales en la configuración de una estética dramática específica y original, en perfecta consonancia con la que Valle había logrado elaborar en castellano. 


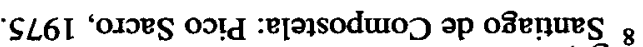
$966 I^{\prime} \mathrm{BBO} / \mathrm{ED}$

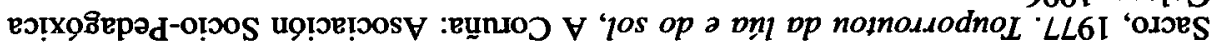

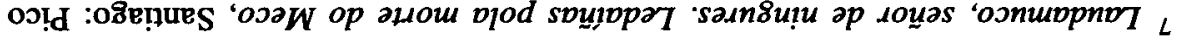

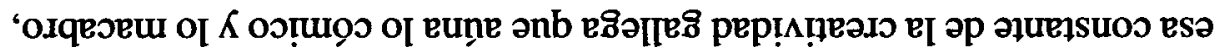

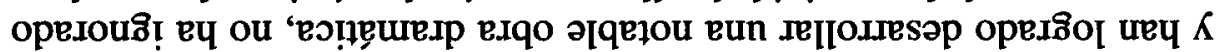

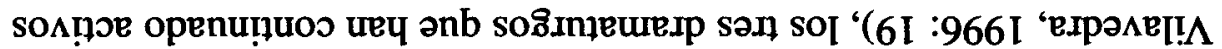

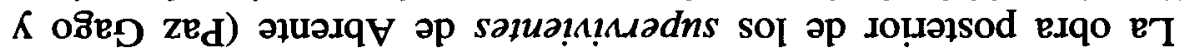

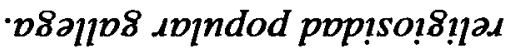

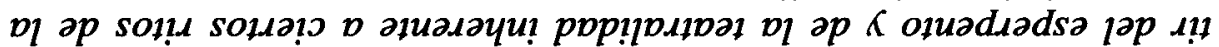
-ıd $v$ nq

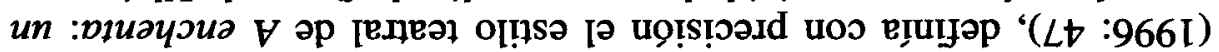

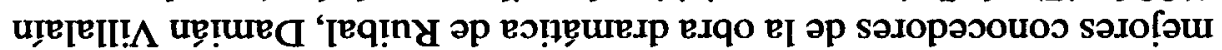

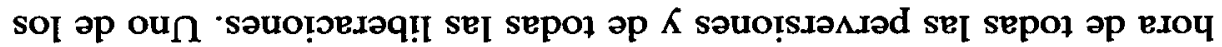

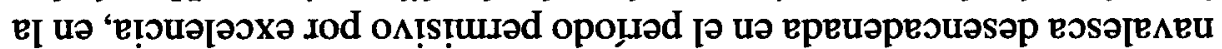

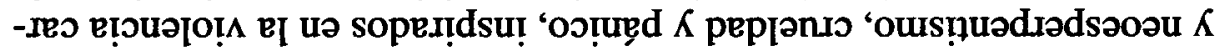

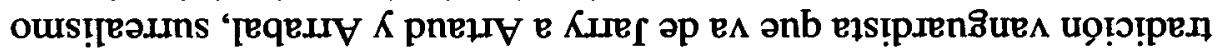

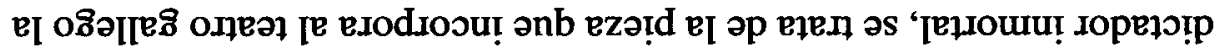

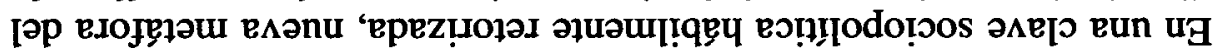

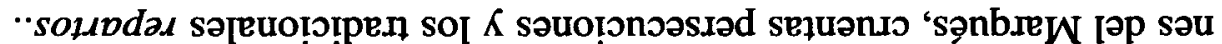

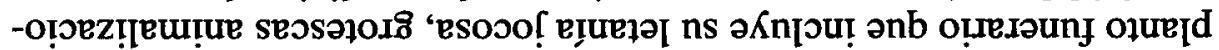

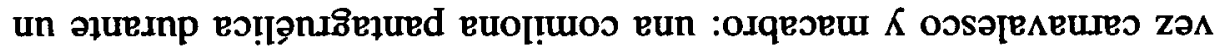

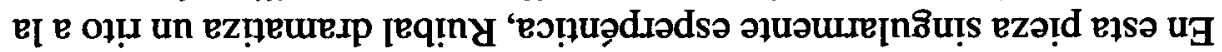

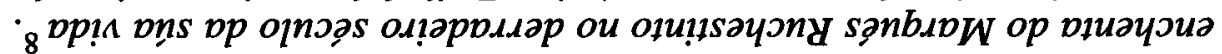

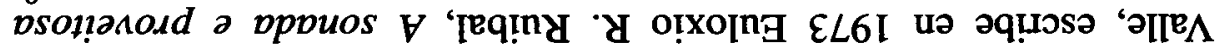

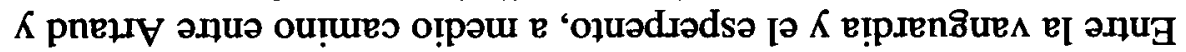

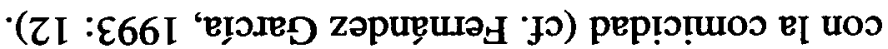

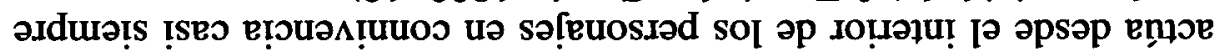

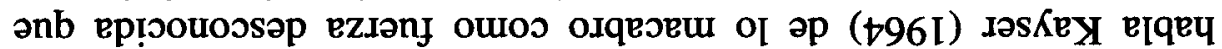

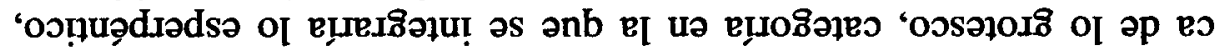

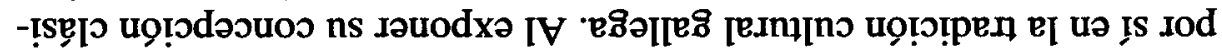
әр sope!!!

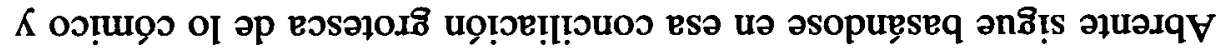

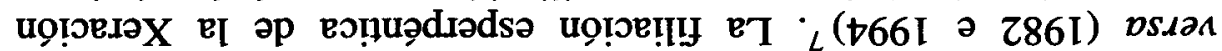

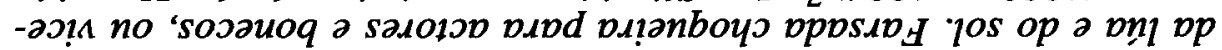

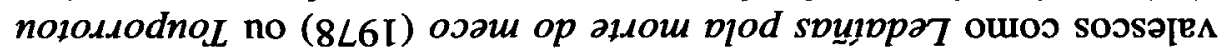

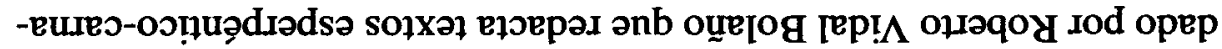

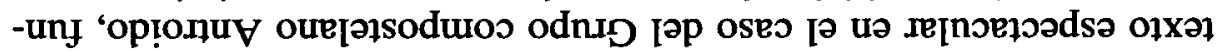

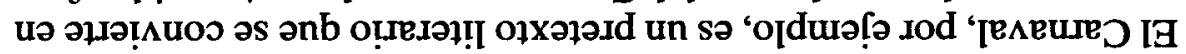


permaneciendo fiel a una estética dramática peculiar que la crítica ha consagrado con un nuevo ismo: el neoesperpentismo, común a Ruibal, Vidal Bolaño y Manuel Lourenzo.

Los abundantísimos ingredientes rituales de la tradición cultural gallega, los que conforman tanto lo que Risco (1979: 414 y 633) ha llamado una auténtica Leyenda de la Muerte como los que configuran un verdadero Misterio del Antroido de origen medieval, lo macabro y lo festivo, se convierten en ingredientes constitutivos del discurso escénico de estos dramaturgos. No son simples motivos temáticos de interés folclórico, sino aspectos esenciales de la propuesta espectacular que hacen los miembros de Abrente y de este modo, a partir de la coincidencia de materiales culturales y rituales explotados, su Poética teatral viene a coincidir con la Poética valleinclaniana. Al analizar el lenguaje dramático de Divinas Palabras, el dramaturgo Euloxio R. Ruibal (1998: 41) lo caracterizaba precisamente desde este punto de vista: Unha linguaxe ritualizada (cancións, prantos, conxuros, aturuxos...) reforza o núcleo temático, tan recorrente en Valle, formado pola avaricia, a luxuria e a morte, moi interrelacionadas e enlazadas.

Uno de sus más legítimos herederos hacía su particular homenaje a Ramón María del Valle-Inclán escribiendo y dirigiendo Doentes, un texto en relación quizás demasiado directa con el esperpento mayor de Valle, Luces de Bohemia. Roberto Vidal Bolaño ya había sido finalista del Tirso de Molina con Réquiem, versión castellana de este magnífico remake que mereció el Premio Rafael Dieste de la Diputación coruñesa en 1997. Quizás sea demasiado estrecho el contacto intertextual, quizás sea excesivo o demasiado explícito el tributo estético y temático al autor de Luces, pero ese reproche de buena parte de la crítica habla por sí solo del mimetismo, de la identificación entre el dramaturgo compostelano y el de Villanueva de Arousa.

La prosa artificiosa y el discurso sabiamente retorizado de las acotaciones, el dinamismo bien ensayado en Días sen gloria (1992) o las técnicas de la narrativa fílmica que llevaron al crítico Manuel Quintáns a caraterizar su estilo como neoesperpentismo cinematográfico, son rasgos que Vidal Bolaño imprime naturalmente a todos sus textos. La articulación de las escenas en breves secuencias fílmicas contribuye a provocar la angustiosa idea de movimiento, el dinamismo vertiginoso y la multiplicación del espacio que exhiben Días sen gloria, As actas oscuras (1993) o Doentes haciendo realidad la inquietud de Valle, empeñado en adaptar y superar las técnicas del cinematógrafo al 
espectáculo teatral, para garantizar su supervivencia ante la competencia desleal de la pantalla grande.

En otro lugar hemos hablado de la constitución, en la actualidad, de lo que podemos llamar una «Comedia Nacional Gallega» (Paz Gago, 1998b), cuyos ingredientes esenciales serían las tendencias surrealistas, los variados registros del absurdo y el expresionismo, todo ello sintetizado en el neoesperpentismo gallego peculiar. Se inscriben en este género textos de autores gallegos contemporáneos en los que se critican paródicamente aspectos de la sociedad gallega actual, mediante una estética teatral basada en el esperpento y en el absurdo. Miguel Anxo Murado, Gustavo Pernas, Raúl Dans o Xavier Lamas forman este grupo que todavía no asume rasgos generacionales nítidos.

En Historias Peregrinas, texto del escritor Miguel Anxo Murado lleno de humor e ironía, se pone en escena una intriga hilarante a partir de la investigación a un actor de una modesta compañía de cómicos de la legua escondido tras los bastidores de un carro ambulante. Intriga de la identidad y la alteridad que teje este misterioso personaje, el comediante convertido en hombre anónimo sobre cuya personalidad multiforme organizan sus colegas una delirante pesquisa: de ladrón a príncipe azul, pasando por el mismísimo Apóstol Santiago, el comediante resulta ser un fugitivo de la justicia que se esconde tras los bastidores del teatrillo ambulante infringiendo sistemáticamente las fronteras metafísicas de la ficción escénica y la realidad teatral, la ilusión y la verdad. En un doble gesto paródico y especular, los actores de Teatro do Noroeste Luma Gómez, Belén Constenla y Ernesto Chao daban vida a los torpes actores ambulantes que a su vez encarnan las alegorías de los autos medievales, desmitificándolas con eficaz humor cuasi-expresionista.

También el primer texto dramático de Suso de Toro, Una rosa é unha rosa, constituye una comedia efectista que parodia la sociedad actual con todos sus tics, desde la teleadicción al hiperconsumismo. Las aportaciones tópicas de la modernidad y la postmodernidad -el teatro dentro del teatro o la invasión de éste por los medios audiovisuales- se añade aquí una fórmula paródica muy original: el telefilme dentro del teatro. Parodia de los excesos cotidianos, la pieza se recrea en la confusión entre realidad escénica y realidad virtual. Puesta en escena postmoderna, muy acorde con el texto y el contexto, escenografía e interpretación se inspiran en el cómic y la marioneta, explotando esperpénticamente los ingredientes estéticos de las diversas tribus urbanas. 
Comicidad literalmente esperpéntica utiliza Gustavo Pernas en sus textos: Si $O$ galego, a mulata e o negro (1990) exhibía la característica comicidad neoesperpéntica, la trilogía formada por Ladraremos (1996), Fábula. Comedia nun só acto...sexual (1997) y Anatomía dun hipocondríaco. Comedia médica (1998) confirman esa tendencia dramatúrgica que hemos denominado Comedia Nacional Gallega.

Como en otros casos, Gustavo Pernas representa la simbiosis de texto y representación, pues tiene la oportunidad de montar sus textos con su propia Productora, Áncora Produccións. Humor ácido e ironía inteligente se dan cita en estas visiones críticas de las paranoias que produce en el individuo la sociedad actual: hábitos televisivos, incomunicación, sexo, culto al físico, hipocondrismo... Estructurado a la medida de estas piezas cuidadosamente trabajadas en el escritorio, es admirable la labor actorial de los componentes de Áncora en estos espectáculos, en los que se juega con la duplicidad de las personalidades, registros interpretativos múltiples y la expresión gestual que se desplaza vertiginosamente de la risa al llanto, de la comicidad hilarante al dramatismo depresivo.

La animalización, tan propia de Valle, llega a su paroxismo en Ladraremos, donde asistimos a un esfuerzo antológico en la dicción de ladridos, difícil ejercicio hábilmente sostenido por un mendigo y una fantasiosa señora algo cursi, los solitarios protagonistas de este drama absurdo que dialoga eficazmente con el mejor teatro europeo, de Valle a Albee. De nuevo la heterología, la pluralidad de discursos y de registros dramáticos, seduce a un espectador que percibe las fronteras borrosas entre la locura y la razón, la realidad y la ilusión. Un tono más intelectualizado muestra el extraordinario texto de Anatomía, hábilmente plasmado en el último espectáculo de Áncora Produccións. El minucioso análisis plástico de un cuadro clásico sirve de intertexto lúdico-erudito a la anécdota de dos personajes atormentados por las enfermedades reales o imaginarias que inventa y reinventa la sociedad contemporánea. Como se evidenciaba en Fábula, Gustavo Pernas mezcla intencionalmente registros estilísticos y genéricos diversos (cómico, trágico y tragicómico; farsa, parodia y sátira) con el fondo de expresionismo esperpéntico propio de la nueva dramaturgia gallega.

Si la obra dramática de Raúl Dans recoge los rasgos del mundo valleinclaniano, desde Matalobos (1993) hasta Cita co diaño (1998), es sin duda Xavier Lama quien representa una verdadera reencarnación literaria del autor de las Comedias Bárbaras. Tanto la prosa artificiosa y agriamente retorizada, como los personajes atormentados y 
marginales, víctimas de todos los procesos de animalización, cosificación y caricaturización propios del género, las situaciones grotescas y las acciones, la atmósfera paródica y la ambientación, convierten a Xavier Lama en un perfecto trasunto de Valle, un Valle en gallego, trasunto tan perfecto que no hay ni mimetismo ni imitación, sino la misma genialidad, la misma fuerza inspirada del mayor dramaturgo español del siglo. Dos piezas rotundas son suficientes para anunciar este nuevo reinventor del esperpento: $O$ peregrino errante que cansou ó demo (1993) y $O$ serodio remordimento do amor (1997).

En las Aclaraciones con las que el dramaturgo gallego Lauro Olmo abría el Homenaje del Ateneo de Madrid a uno de los más insignes ateneístas, en su condición de director de la cátedra que lleva el nombre del arosano, encontramos estas palabras clarificadoras: Los que, con mayor o menor fortuna, nos dedicamos al arte de la expresión - pluma en mano- estamos en deuda con don Ramón María del Valle-Inclán. Directa o indirectamente, a todos nos ha llegado su influencia (1991: 11). Esa influencia es directísima en el caso de los autores gallegos que optaron por escribir en su lengua, porque nadie supo expresar como Valle, aunque en una lengua híbrida, las concepciones del mundo y el mundo del hombre gallego.

\section{Referencias bibliográficas}

AA.VV. (1991). Valle-Inclán. Homenaje del Ateneo de Madrid. Madrid: Exadra de Ediciones.

Alonso Montero, X. (1971). Castelao, Galicia y Valle-Inclán. Lugo: Celta. AMOR Y VÁZqUEZ, J. (1992). «De regionalismo y literatura: Yeats y ValleInclán». En Suma Valleinclaniana, Gabriele, J. P. ed., 267-280. Barcelona: Anthropos y Consorcio de Santiago.

Bobes NAVES, M. C. (1987). Semiología de la obra dramática. Madrid: Taurus. BoREL, J. P. (1966). El teatro de lo imposible. Madrid: Guadarrama.

CAllen, A. (1969). «Stoppard's Godot: Some French Influences on Pos-War English Drama». New Theatre Magazine 10/1, 22-30.

CARBallo CALERo, R. (1964). «A temática galega na obra de Valle-Inclán». Grial, 3.

- (1981). «Sobre as fontes literarias de Os vellos de Castelao». Colóquio/Letras, 64. En 1984, 235-240.

- (1982). Libros e autores galegos. Século XX. A Coruña: Fundación Pedro Barrié de la Maza. 
- (1983). «Sobre Os vellos non deben de namorarse». Cadernos da Escola Dramática Galega 33. En 1984, 227-234.

- (1984). Letras Galegas. A Coruña: Agal.

CORTEZÓN, D. (1991). «Castelao y la condición gallega de Valle-Inclán». En Valle-Inclán. Homenaje del Ateneo de Madrid, 325-346. Madrid: Exadra de Ediciones.

DunCaN, J. E. (1981). «Godot Comes: Rosencrantz and Guildenstern are Dead». Ariel 12/4, 57-70.

EssLin, M. (1969). The Theatre of the Absurd. New York: Doubleday \& Co. FERNÁNDEZ GARCÍA, M. N. (1993). El universo del esperpento en ValleInclán. Valladolid: Aceña.

HARDISSON, F. (1992). «Valle-Inclán y Artaud, hermanos bajo la piel». En Suma Valleinclaniana, Gabriele, J. P. ed., 177-196. Barcelona: Anthropos y Consorcio de Santiago.

HuTCHEON, L. (1983). «The Carnivalesque and Contemporary Narrative: Popular Culture and the Erotic». Revue de l'Université d'Ottawa 53, 88-94. JACQUART, E. (1974). Le Théâtre de dérision. Beckett, Ionesco, Adamov. París: Gallimard.

JACQUART, E. (ed.) (1991). Eugène Ionesco. Théâtre complette. París: Gallimard.

KAYSER, W. (1964). Lo grotesco. Su configuración en Pintura y Literatura. Buenos Aires: Nova.

LaubreauX, R. ed. (1973). Les critiques de notre temps et Ionesco. París: Garnier.

Lourenzo, M (1991). «Cunqueiro en el teatro gallego». Primer Acto 241, 34-38.

- (1993). «Algúns aspectos da teatralidade de Cunqueiro». En Congreso Álvaro Cunqueiro, 503-508. Santiago: Xunta de Galicia.

Lourenzo, M. e Pillado, F. (1979). O teatro galego. A Coruña: Edicións do

Castro.

- (1982). Antoloxía do teatro galego. A Coruña: Edicións do Castro.

- (1987). Dicionário do teatro galego, 1671-1985. Santiago: Sotelo Blanco.

Lourenzo, M. y TATo, L. (1997). Grupo Nós: O teatro, Historia da Literatura Galega,.$^{\circ} 25$, A Nosa Terra.

Olmo, L. (1991). «Aclaraciones». En Valle-Inclán. Homenaje del Ateneo de Madrid, 9-13. Madrid: Exadra de Ediciones.

PAZ-ANDrade, V. (1982). Castelao na luz e na sombra. A Coruña: Edicións do Castro.

PaZ GAGO, X. M. (1993). «Os proxectos teatrais de Cunqueiro, as pezas curtas». En Congreso Álvaro Cunqueiro, 461-469. Santiago: Xunta de Galicia.

- (1998a). «Una triste polémica: Valle-Inclán en Galicia». Primer Acto $274,48-55$.

- (1998b). «Tendencias no Teatro galego actual». Ensaio 2, 20-27.

- (1999). O Teatro de Álvaro Cunqueiro. Santiago de Compostela: Instituto Galego de Artes Escénicas e Musicais. 
Paz Gago, X. M. ed. (1996). Teatro Gallego. Primer Acto (Número Monográfico) 262.

Paz Gago, X. M. y Vilavedra, D. (1996). «El teatro gallego actual». Primer Acto 262, 18-23.

PILlado, F. (1999). «Álvaro Cunqueiro. Bibliografía teatral». CasaHamlet 1, 86-95.

Pronko, L. (1962). Avant-Garde. The Experimental Theatre in France. Berkeley and Los Angeles: California University Press.

Risco, V. (1979). «Etnografía: cultura espiritual». En Historia de Galiza, Otero Pedrayo, R. (ed.), 255-762. Madrid: Akal.

Ruibal, E. R. (1998). «Mito e símbolo en Divinas palabras». En Galicia nos tempos do 98, 39-44. A Coruña: Xunta de Galicia.

SAlVAT, R. (1993). "Cunqueiro y el teatro europeo de su tiempo». En Congreso Álvaro Cunqueiro, 451-460. Santiago de Compostela: Xunta de Galicia.

Trewin, J. C. (1971). Brooks: A Biography. Londres: MacDonald.

Vilavedra, D. y Salgado, X. M. (1991). Álvaro Cunqueiro. A Coruña: Xunta de Galicia.

Villalaín, D. (1991a). «Don Hamlet: Cunqueiro ante o público». Grial 112, 635-636.

- (1991b). «Don Hamlet en el Centro Dramático Gallego». Primer Acto 241, 57-59.

- (1996). «El teatro de Euloxio R. Ruibal». Primer Acto 262, 46-49.

- (1993). «O teatro de Cunqueiro: un achegamento pluridimensional». En Congreso Álvaro Cunqueiro, 479-490. Santiago: Xunta de Galicia. 